\title{
An experimental investigation of asphaltene stability in heavy crude oil during carbon dioxide injection
}

\author{
Sherif Fakher ${ }^{1} \cdot$ Mohamed Ahdaya $^{1} \cdot$ Mukhtar Elturki $^{1} \cdot$ Abdulmohsin Imqam $^{1}[$
}

Received: 16 July 2019 / Accepted: 19 September 2019 / Published online: 25 September 2019

(c) The Author(s) 2019

\begin{abstract}
Carbon dioxide $\left(\mathrm{CO}_{2}\right)$ injection is one of the most applied enhanced oil recovery methods in the hydrocarbon industry, since it has the potential to increase oil recovery significantly and can help reduce greenhouse gases through carbon storage in hydrocarbon reservoirs. Carbon dioxide injection has a severe drawback, however, since it induces asphaltene precipitation by disrupting the asphaltene stability in crude oil that bears even the slightest asphaltene concentration. This can result in severe operational problems, such as reservoir pore plugging and wellbore plugging. This research investigates some of the main factors that impact asphaltene stability in crude oil during $\mathrm{CO}_{2}$ injection. Initially, asphaltene precipitation, flocculation, and deposition were tested using visual tests without $\mathrm{CO}_{2}$ in order to evaluate the effect of oil viscosity and temperature on asphaltene stability and content in the crude oil. The results obtained from the visualization experiments were correlated to the Yen-Mullins asphaltene model and were used to select the proper chemical to alter the oil's viscosity without strongly affecting asphaltene stability. After performing the visual asphaltene tests, a specially designed filtration vessel was used to perform the oil filtration experiments using filter membranes with a micron and nanometer pore size. The effect of varying $\mathrm{CO}_{2}$ injection pressure, oil viscosity, filter membrane pore size, and filter membrane thickness on asphaltene stability in crude oil was investigated. The results were then correlated with the Yen-Mullins asphaltene model to characterize the asphaltene size within the oil as well. Results showed that as the oil viscosity increased, the asphaltene concentration in the oil also increased. Also, the asphaltene concentration and filter cake thickness increased with the decrease in filter membrane pore size, since the asphaltene particles either plugged up the smaller pores, or the asphaltene nanoaggregates were larger than the pore sizes, and thus the majority of them could not pass. This research studies asphaltene instability in crude oil during $\mathrm{CO}_{2}$ injection in different pore sizes, and correlates the results to the principle of the Yen-Mullins model for asphaltenes. The results from this research can help emphasize the factors that will impact asphaltene stability during $\mathrm{CO}_{2}$ injection in different pore sizes in order to help reduce asphaltene-related problems that arise during $\mathrm{CO}_{2}$ injection in hydrocarbon reservoirs.
\end{abstract}

Keywords Asphaltene stability $\cdot$ Carbon dioxide injection $\cdot$ Unconventional shale oil reservoir

\section{Introduction}

$\mathrm{CO}_{2}$ has had significant success in increasing oil recovery from conventional oil reservoirs (Fakher et al. 2017, 2018b, 2019). It has been noted that high molecular weight components in the reservoir oil, such as asphaltene and resins, are not mobilized by the $\mathrm{CO}_{2}$ during flooding, and hence the components precipitate from the oil phase and deposit into the pore spaces, which in turn results in pore plugging and

Abdulmohsin Imqam

ahikx7@mst.edu

1 Missouri University of Science and Technology, Rolla, MO, USA a lower-than-expected oil recovery (Wang et al. 2016; AlGhazi and Lawson 2007; Forte and Taylor 2014; Goual and Abudu 2009; Mendoza De La Cruz et al. 2009; Escobedo and Mansoori 1997). The main reason behind the inability of the $\mathrm{CO}_{2}$ to mobilize the asphaltene is linked to its stability conditions in the crude oil at the reservoir pressure and temperature (Kalantari-Dahagi et al. 2006; Goual 2012; Kord et al. 2012; Lichaa and Herrera 1975; Miadonye and Evans 2010). Asphaltenes are present in the crude oil as micelles, which are stabilized by resins, and maltenes, which surround the asphaltene molecules, while their aliphatic tails are comingled in the oil phase (Thomas et al. 1995; Groenzin and Mullins 2000; Hernandez 1983; Leontaritis and Mansoori 1987; Punase et al. 2016; Mannistu et al. 1997). A change 
in the reservoir conditions that alters or disrupts the equilibrium conditions such as a change in temperature, pressure, or introduction of a foreign agent such as $\mathrm{CO}_{2}$ in the reservoir causes the precipitation and eventually the deposition of asphaltene in the pores (Zendehboudi et al. 2014; KalantariDahagi et al. 2006; Kariznovi et al. 2012; Mansoori 1996; Uetani 2014; Rogel et al. 1999; Rassamdana et al. 1996). Asphaltene instability can also result due to reservoir rock properties such as lithology and pore size (Kordestany et al. 2019; Shedid and Zekri 2006; Mishra et al. 2012; Hannisdal et al. 2006; Jha et al. 2014).

Much research has been conducted to study the precipitation and deposition of high molecular weight components, mainly asphaltene, in the pore spaces of conventional oil reservoirs. Zendehboudi et al. (2014) showed the difference between phase precipitation and phase deposition by defining precipitation as the formation of the solid phase from the liquid phase, and deposition as the adherence or adsorption of the solid phase to the reservoir rock, which usually occurs after precipitation. Asphaltene can also form flocculations on the rock surface. The flocculations can break up during the process of dissociation and plug the pore throats in the reservoir (Kim et al. 1990; Monger and Fu 1987; Rassamdana et al. 1996). Soroush et al. (2014) showed that below $\mathrm{CO}_{2}$ minimum miscibility pressure (MMP), the pore plugging damage will be much lower compared to above the MMP. This is due to the resins that stabilize the asphaltene being much more unstable above $\mathrm{CO}_{2}$ MMP. KalantariDahagi et al. (2006) reported that the amount of asphaltene deposition in carbonate cores reached the maximum at the oil bubble point. Asphaltene has also been shown to be much more severe as the oil viscosity increases due to the higher concentration of high molecular weight components (Fakher and Imqam 2018, 2019; Fakher et al. 2018a; Fakher 2019). Many methods have therefore been proposed to detect asphaltene deposition in conventional oil reservoirs, such as the De Boer plot (De Boer et al. 1995), asphaltene resin ratio approach (Jamaluddin et al. 2000), colloidal instability index (Yen et al. 2001), filtration, acoustic resonance technique, light scattering technique (Akbarzadeh et al. 2007; Jamaluddin et al. 2000; Speight 1999; Speight et al. 1985), optical spectroscopy (Kharrat et al. 2013), nuclear magnetic resonance (Wang et al. 2016), SARA analysis (Fan et al. 2002; Goel et al. 2017; D-4124-97 2019), and chromatography (Jewell et al. 1972; Islas-Flores et al. 2005; Keshmirizadeh et al. 2013).

Recently, $\mathrm{CO}_{2}$ flooding has been conducted to increase oil recovery from unconventional shale reservoirs. However, very little research work has been conducted to study and evaluate how the asphaltene in the crude oil will behave in micro and nano pores during $\mathrm{CO}_{2}$ injection. Moradi et al. (2012) ran experiments using a $0.2-\mu \mathrm{m}$ pore size filter membrane using nitrogen and methane and concluded that asphaltene deposition was much more severe in methane than into nitrogen. They did not use $\mathrm{CO}_{2}$ in their study. Mohammed et al. (2017) performed a simulation study to model asphaltene deposition in the low permeability reservoirs during $\mathrm{CO}_{2}$ flooding and sought to optimize $\mathrm{CO}_{2}$ injection by suggesting cyclic $\mathrm{CO}_{2}$ flooding with brine. Shen and Sheng (2018) studied asphaltene deposition in Eagle Ford shale reservoir using cyclic gas injection. They used filter membranes of $30 \mathrm{~nm}, 100 \mathrm{~nm}$, and $200 \mathrm{~nm}$ to study asphaltene precipitation and deposition. The experiments they conducted with the filter membranes were conducted at $50 \mathrm{psi}$ and room temperature. They did not, however, report the mechanism by which the asphaltene precipitates, deposits, and plugs the nanopores of the shale. Sun et al. (2019) investigated $\mathrm{CO}_{2}$ and nitrogen competitive adsorption to asphaltene in nanopores in an attempt to investigate the feasibility of using asphaltene as a means of carbon capture in nanopores during $\mathrm{CO}_{2}$ injection.

Based on the aforementioned literature review, very little research has been conducted to evaluate asphaltene instability in the crude oil during $\mathrm{CO}_{2}$ injection in unconventional reservoirs with nanopores. This research performs several asphaltene visualization experiments, to investigate the impact of temperature and oil viscosity on asphaltene precipitation and deposition with time, and then undergoes oil filtration experiments during $\mathrm{CO}_{2}$ injection using nanofilter membranes to evaluate asphaltene instability when the oil is mobilized through the nanopores. This research can help shed light not only on the factors that impact asphaltene instability in the crude oil during $\mathrm{CO}_{2}$ injection, but also quantify the impact of each factor through asphaltene concentration measurements.

\section{Yen-Mullins asphaltene model}

The Yen-Mullins model is currently the most widely accepted asphaltene model, shown in Fig. 1 (Mullins 2011). This model describes the Yen-Mullins asphaltene structure based on size and behavior as a function of the crude oil that bears the asphaltene. In light oils with high API gravity, the asphaltenes will be present as small poly-aromatic hydrocarbon molecules with an average diameter of $1.5 \mathrm{~nm}$. In this case, the asphaltene concentration will be relatively low, and thus the asphaltene size will not grow. In black oils with slightly less API gravity, the asphaltene concentration will be higher and thus the asphaltene will be present in the form of nanoaggregates with an average diameter of $2 \mathrm{~nm}$, which is slightly larger than the asphaltene present in the light oil. In heavy oils with extremely low API gravity, the asphaltene concentration will be relatively high, and will thus begin to form clusters. These clusters will grow in size and will reach an average diameter of $5 \mathrm{~nm}$. The clusters 


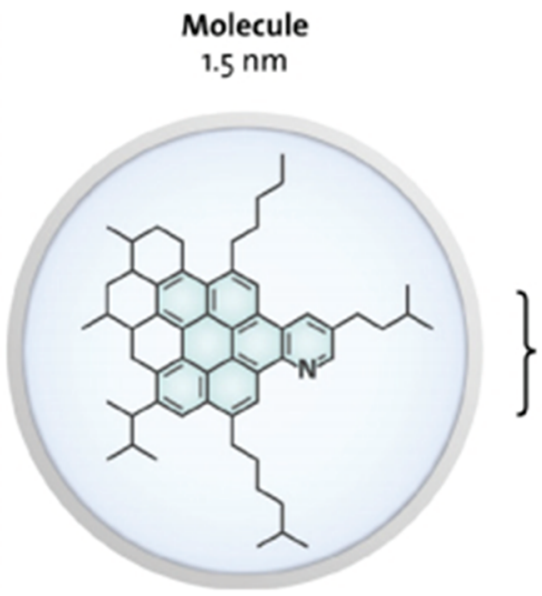

Light Oil: Asphaltene concentration is low. Isolated Molecules

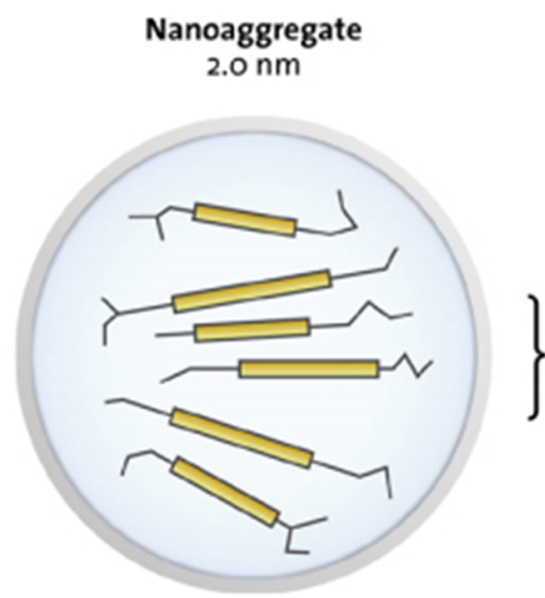

Black Oil: Asphaltene concentration is moderate.

Nanoaggregates

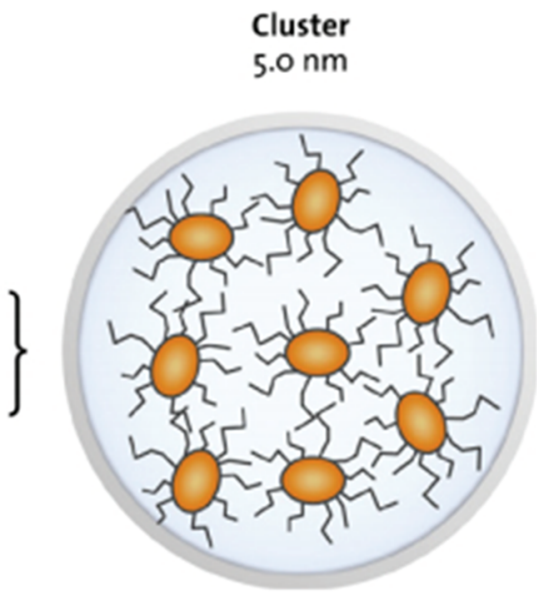

Heavy Oil: Asphaltene concentration is high. Aggregated Clusters

Fig. 1 Yen-Mullins asphaltene model (Mullins 2011)

form from the combination of several nanoaggregates together. Based on this model, as the asphaltene concentration in the oil increases, the oil will become heavier due to the high molecular weight of asphaltenes and thus its API will decrease, which shows that asphaltenes have an overall negative impact. The Yen-Mullins asphaltene model will be used to describe the results for the asphaltene visualization tests in order to illustrate the impact of oil viscosity on the asphaltene concentration in the crude oil.

\section{Experimental material}

\section{Crude oil}

Crude oil with viscosities 469, 260.7, 119, and $63.7 \mathrm{cp}$ were used to run the experiments that were conducted. The crude oil composition was identified using gas chromatography/ mass spectrometry. The exact composition is shown in Table 1.

\section{Carbon dioxide}

A high-pressure $\mathrm{CO}_{2}$ cylinder with purity $99.99 \%$ was connected to the filtration setup directly and used for $\mathrm{CO}_{2}$ injection.
Table 1 Crude oil composition and asphaltene concentration

\begin{tabular}{lc}
\hline Component & $\begin{array}{c}\text { Weight } \\
\text { percent- } \\
\text { age (\%) }\end{array}$ \\
\hline $\mathrm{C}_{1}-\mathrm{C}_{5}$ & 9.37 \\
$\mathrm{C}_{6}-\mathrm{C}_{10}$ & 14.74 \\
$\mathrm{C}_{10}-\mathrm{C}_{15}$ & 18.89 \\
$\mathrm{C}_{16}-\mathrm{C}_{20}$ & 19.31 \\
$\mathrm{C}_{20}-\mathrm{C}_{30}$ & 11.63 \\
$\mathrm{C}_{30+}$ & 26.06 \\
Total & 100 \\
Asphaltene (component of $\left.\mathrm{C}_{30+}\right)$ & 5.73 \\
Asphaltene precipitant & Heptane \\
& $(10 \mathrm{ml}$ \\
& per \\
& $0.1 \mathrm{ml}$ \\
\hline
\end{tabular}

\section{Filter membrane}

Filter membranes with pore sizes of $2.7 \mu \mathrm{m}, 100 \mathrm{~nm}, 10 \mathrm{~nm}$, and $0.2 \mathrm{~nm}$ were used in this study to cover a broad range of pore sizes.

\section{Specially designed LPLT filtration vessel}

A filtration vessel was used to be able to accommodate the nanofilter membranes, the crude oil, and the $\mathrm{CO}_{2}$ with no leakages. 


\section{Rheometer}

A rheometer was used to measure the viscosity of the different crude oils that were used to conduct the experiments.

\section{Experimental setup}

Figure 2 illustrates the setup used to conduct the experiments. It is comprised of a high-purity $\mathrm{CO}_{2}$ cylinder for $\mathrm{CO}_{2}$ injection, a pressure regulator attached to the cylinder to control the pressure provided by the cylinder, a filtration vessel, which contains the crude oil, a rubber O-ring to prevent leakages, the filter membrane, and a 60-micron mesh screen used to support the filter membrane and prevent it from being punctured during the experiment due to high pressure without constricting the flow of oil. The support structure was used to fix the filtration vessel at a sufficient height in order to leave space for the test tube used to collect the oil produced from the effluent. The fixation screw helped tightly fix the top cover of the filtration vessel tightly to prevent leakages. The oil that was produced during the experiment will be referred to as the filtrate, while the oil that was not produced will be referred to as the filtride.

\section{Experimental procedure}

Two sets of experiments were conducted in this research. These include the asphaltene visualization experiments and the asphaltene filtration experiments. The experimental procedure for each experiment is explained in this section.

\section{Asphaltene visualization experiments}

The asphaltene visualization experiments were conducted using the following procedure:

1. $0.1 \mathrm{ml}$ of crude oil was added to the test tube. The volume was measured using a high-accuracy needle and a balance to ensure that all samples were the same.

2. $10 \mathrm{ml}$ of heptane was then added to the crude oil in the test tube. The test tube was then shaken vigorously to dissolve the oil in the heptane.

3. The tube was sealed using an O-ring and a threaded cap to ensure that no heptane would evaporate and leave the test tube, especially at high temperatures.

4. The test tube was placed in an isothermal water bath and was removed when the pictures were taken and then placed immediately in the water bath again.

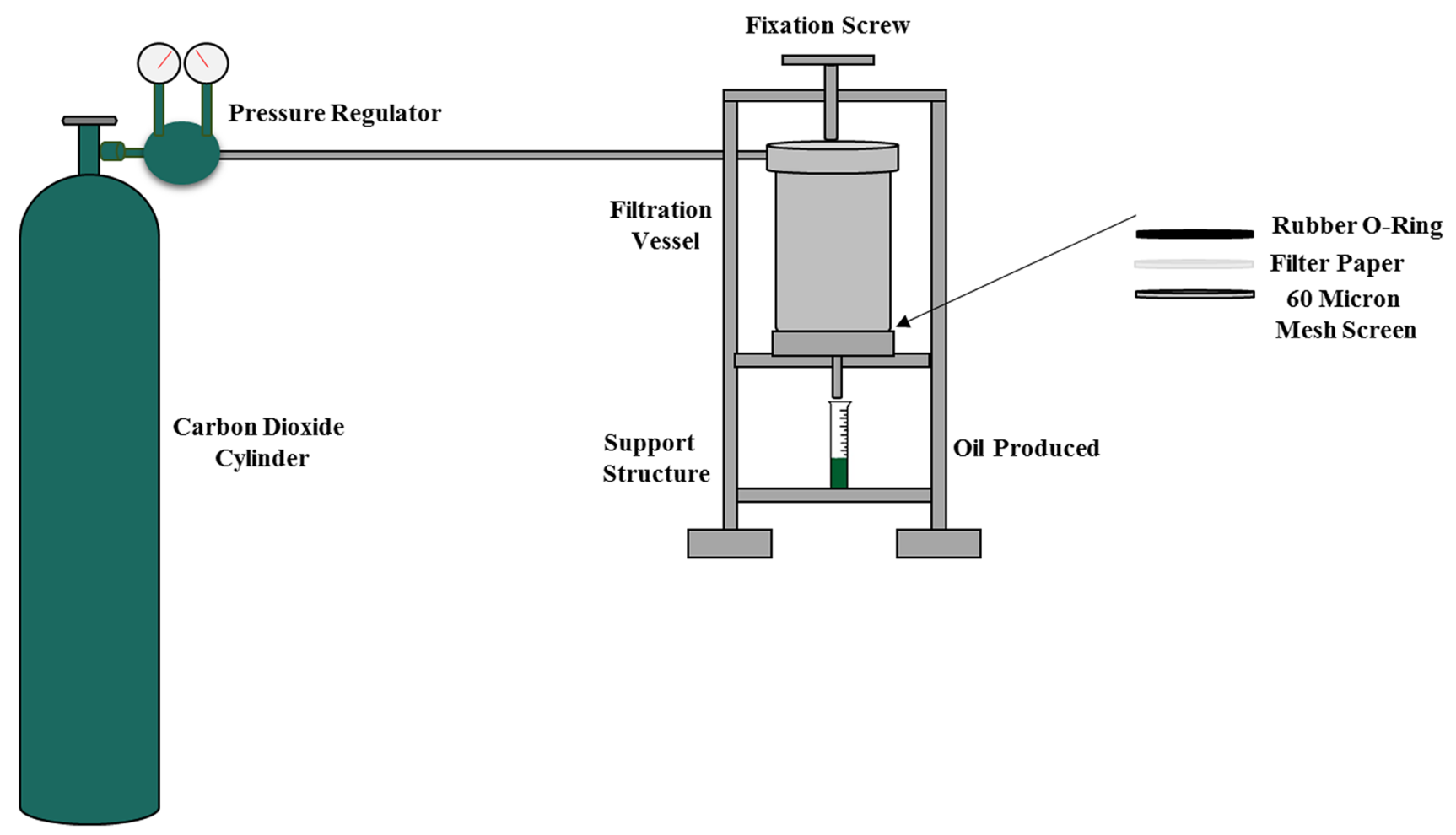

Fig. 2 Specially modified filtration setup 


\section{Asphaltene filtration experiments}

The following procedure was followed to conduct the asphaltene filtration experiments:

1. The filtration vessel was prepared by placing a mesh screen, filter membrane, and rubber O-ring on the bottom cap in the order mentioned. The bottom cap assembly was then attached to the filtration vessel.

2. $100 \mathrm{ml}$ of crude oil was then poured in the filtration vessel. The top cap was then placed and sealed using a fixation screw.

3. $\mathrm{CO}_{2}$ was injected into the vessel and oil production was recorded with time. The experiment is stopped when no oil production is observed for at least five consecutive minutes.

4. The produced and remaining oil are then collected for asphaltene analysis. The filter membrane is also collected and stored in a vacuum seal for analysis.

\section{Results and discussion}

The results for all the experiments will be discussed in this section. Initially, the asphaltene visualization tests will be discussed, including the oil viscosity and the temperature effects on asphaltene instability in the crude oil. Following this, the filtration experiments results will be discussed, and the asphaltene concentration from different experiments will be provided.

\section{Asphaltene visualization experiments}

Before conducting the actual filtration experiments, asphaltene visualization tests were conducted to visually investigate the impact of crude oil viscosity and temperature on asphaltene stability in the crude oil. Asphaltene visualization tests can prove to be a very significant tool since the test can show how the asphaltene behaves in terms of precipitation and deposition at different conditions. For each experiment, $0.1 \mathrm{ml}$ of crude oil and $10 \mathrm{ml}$ of heptane were mixed. These amounts were used to ensure that the solution was clear enough to accurately visualize the asphaltene precipitation, flocculation, and deposition. It is important to note that in all the images, there is a dark line at the top of the test tube. This line was created when the images were taken due to the reflections and does not represent anything significant.

\section{Oil viscosity effect}

Based on the Yen-Mullins model, which was explained previously, as the oil becomes lighter, the percentage of asphaltene in the oil it will decrease. This was visually observed

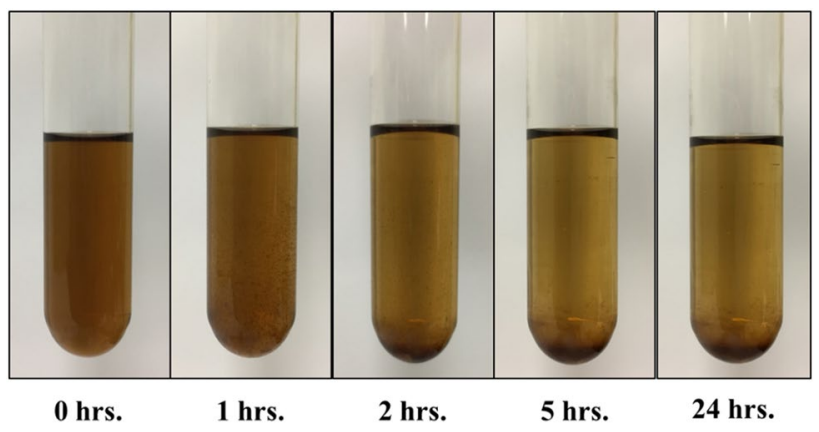

Fig. 3 Asphaltene precipitation and deposition using $178 \mathrm{cp}$ oil

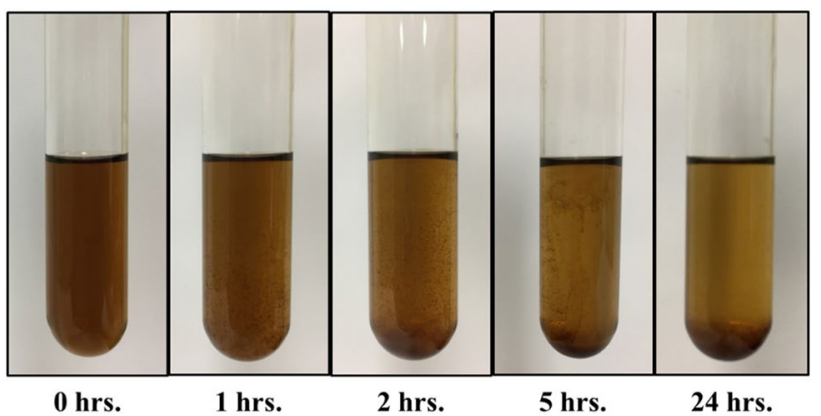

Fig. 4 Asphaltene precipitation and deposition using $75 \mathrm{cp}$ oil

when conducting the asphaltene precipitation and deposition experiments to investigate the impact of oil viscosity on asphaltene stability in the crude oil. The results for crude oil with $178 \mathrm{cp}$ viscosity are shown in Fig. 3. Initially, the asphaltene cannot be seen in the sample due to its partial stability in the crude oil. After $1 \mathrm{~h}$, however, the asphaltene can be seen in the image as it begins to precipitate from the solution. The asphaltene is still suspended in the sample, however, and has not yet deposited. As time progresses, two significant observations can be made. More asphaltene can be observed in the bottom of the test tube, which signifies asphaltene deposition. The asphaltene begins to form dense flocculations that then deposit to the bottom of the tube. The second important observation is that as the asphaltene deposits, the sample becomes lighter in color in all the sections, while the bottom-most section becomes extremely dark in color due to the high concentration of asphaltene in this section. This shows that asphaltene precipitation and flocculation will not occur immediately, but rather occur with time. This is extremely important for field application since it shows that asphaltene precipitation is a stage-wise process. If precipitation is detected early, it can be mitigated before flocculation takes place.

A lighter crude oil with a viscosity of $75 \mathrm{cp}$ was also investigated, shown in Fig. 4. The same observations that were made in the heavier crude oil, shown in Fig. 3, were

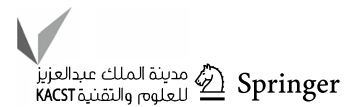


observed. However, the main difference was in the overall color of the sample and the asphaltene concentration present. The lower-viscosity crude oil has a lighter color at all times and was also found to have a lower asphaltene concentration compared to the higher-viscosity crude oil, which agrees with the Yen-Mullins asphaltene model, which was explained previously. This indicates that even low-viscosity crude oils may suffer from asphaltene instability problems. The lower-viscosity crude oil had a lower asphaltene concentration; however, flocculation and deposition still occurred. It is therefore important to undergo asphaltene stability analysis in any crude oil in order to anticipate and avoid asphaltene-related problems.

\section{Temperature effect}

Temperature can have a strong impact on the stability of the asphaltene in the crude oil. As the temperature increases, the oil becomes lighter, thus leading to a higher asphaltene deposition. A comparison of the same sample of crude oil was performed at different temperatures to investigate the impact of temperature on asphaltene stability in the crude oil. Figure 5 shows the results for the oil sample at $40{ }^{\circ} \mathrm{C}$ for $24 \mathrm{~h}$. Initially, no asphaltene can be observed, and the sample color appears to be the same all over. However, as the time progresses, the asphaltene begins to become visual, and the color of the sample begins to become lighter at the top of the test tube and darker at the bottom due to the asphaltene flocculation and deposition. Finally, after $24 \mathrm{~h}$, almost all of the asphaltene has deposited and the sample becomes much lighter in color compared to the initial sample at time zero. Temperature had two main effects on the crude oil. Temperature will decrease the viscosity of the crude oil and thus will reduce its tendency to bear asphaltene. Increasing the temperature will result in a rapid severance of the bond between the resin and asphaltene, which will promote asphaltene precipitation. As the temperature increases, the rate at which this bond is severed will be higher, and thus, the asphaltene will begin to precipitate faster. However, the

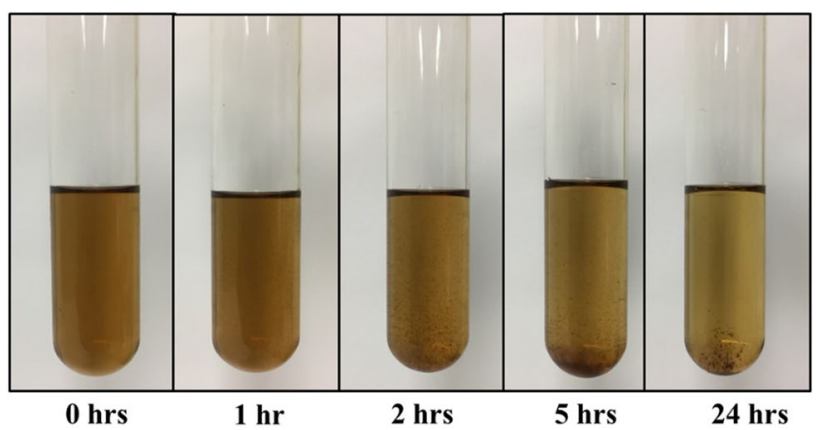

Fig. 6 Asphaltene precipitation and deposition at $60{ }^{\circ} \mathrm{C}$

asphaltene concentration will be lower since the oil viscosity is decreased.

At $60{ }^{\circ} \mathrm{C}$, shown in Fig. 6 , the oil viscosity becomes lower, which in turn results in a lower asphaltene concentration and an overall lighter color for the sample compared to the same sample at $40{ }^{\circ} \mathrm{C}$. This shows that at the higher temperature the asphaltene concentration was impacted, which is evident from the asphaltene shown in Fig. 6 along with the final color of the sample. An important observation to be made is that the color of the samples becomes clearer earlier than the samples used in the $40{ }^{\circ} \mathrm{C}$ experiment. This is due to the rapidity with which the bond between the asphaltene and resin breaks, and the decrease in asphaltene concentration at the higher temperature.

When the sample was tested at $80{ }^{\circ} \mathrm{C}$, as is shown in Fig. 7, the color became even lighter, which is highly evident after $24 \mathrm{~h}$, and the asphaltene concentration also changed compared to the 60 and $40^{\circ} \mathrm{C}$ samples shown in the previous figures. As was observed in the $60^{\circ} \mathrm{C}$ experiment, the sample becomes lighter in color earlier, due to a faster asphaltene precipitation and a lower asphaltene concentration.

In order to provide a clear comparison between the samples at different temperatures, Fig. 8 shows the different samples at different temperatures. The images were all taken after $2 \mathrm{~h}$. As the temperature increased, the color of

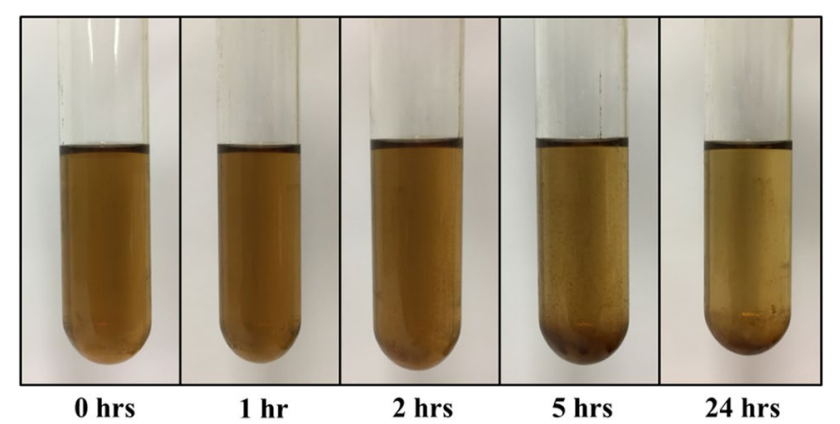

Fig. 5 Asphaltene precipitation and deposition at $40{ }^{\circ} \mathrm{C}$

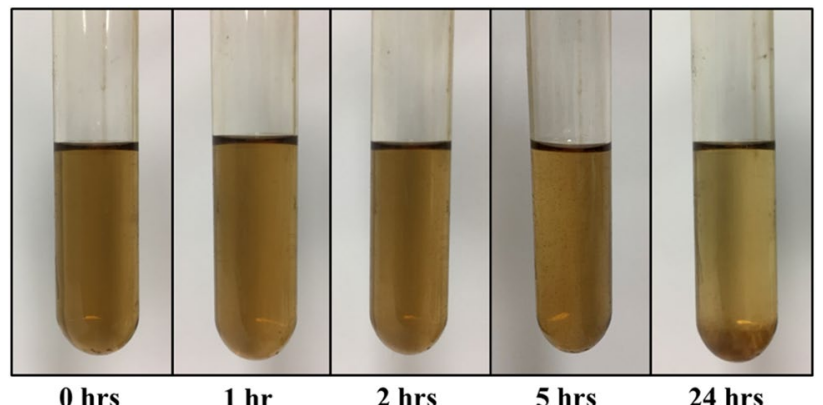

Fig. 7 Asphaltene precipitation and deposition at $80^{\circ} \mathrm{C}$ 


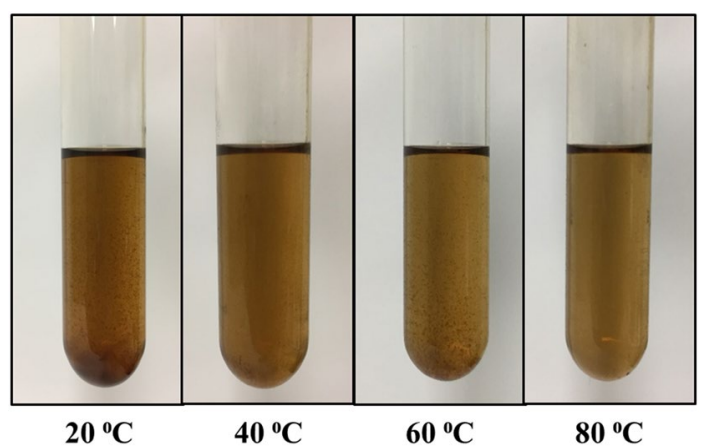

Fig. 8 Asphaltene precipitation and deposition at different temperatures

the sample became lighter due to the change in asphaltene concentration, as was explained previously.

\section{Asphaltene filtration experiments}

Experiments were conducted to study the effect of varying the oil viscosity, $\mathrm{CO}_{2}$ injection pressure, filter membrane thickness, and filter membrane pore size on asphaltene concentration, filter cake thickness, and filter membrane areal filtrate displacement. Table 2 shows the all the experiments conducted in this research and their significant parameters.

Before running the filtration experiments, the asphaltene concentration in the crude oil samples with different viscosity values was determined. This is an extremely important step since it will help in the comparison between the asphaltene concentration in the filtrate and the filtride

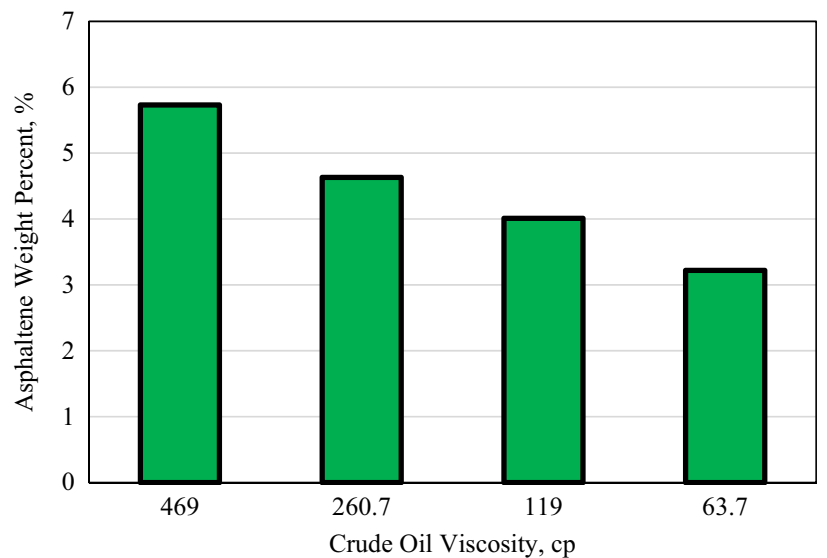

Fig. 9 Asphaltene weight percent in normal crude oil

following the filtration experiments with the crude oil that was not used to conduct any experiments. The asphaltene concentration in the crude oil before running the experiments therefore serves as a reference to signify the change that occurred after conducting the filtration experiments. The asphaltene weight percentage for the different viscosity oils before running the filtration experiments is shown in Fig. 9. As the oil viscosity decreased, the asphaltene weight percentage also decreased, which is supplementary to the Yen-Mullins model. The highest asphaltene weight percentage that was recorded was $5.73 \%$ for the $460 \mathrm{cp}$ oil, whereas the lowest asphaltene weight percent was $3.22 \%$ for the $63.7 \mathrm{cp}$.
Table 2 Description of all experiments conducted in the research

\begin{tabular}{lllll}
\hline Experiment & Oil viscosity $(\mathrm{cp})$ & $\begin{array}{l}\mathrm{CO}_{2} \text { injection pres- } \\
\text { sure (psi) }\end{array}$ & Filter pore size & $\begin{array}{l}\text { Filter thick- } \\
\text { ness (mm) }\end{array}$ \\
\hline 1 & 469 & 25 & $2.7 \mu \mathrm{m}$ & 0.11 \\
2 & 260.7 & 25 & $2.7 \mu \mathrm{m}$ & 0.11 \\
3 & 119 & 25 & $2.7 \mu \mathrm{m}$ & 0.11 \\
4 & 63.7 & 25 & $2.7 \mu \mathrm{m}$ & 0.11 \\
5 & 469 & 50 & $2.7 \mu \mathrm{m}$ & 0.11 \\
6 & 260.7 & 50 & $2.7 \mu \mathrm{m}$ & 0.11 \\
7 & 119 & 50 & $2.7 \mu \mathrm{m}$ & 0.11 \\
8 & 63.7 & 50 & $2.7 \mu \mathrm{m}$ & 0.11 \\
9 & 469 & 100 & $2.7 \mu \mathrm{m}$ & 0.11 \\
10 & 260.7 & 100 & $2.7 \mu \mathrm{m}$ & 0.11 \\
11 & 119 & 100 & $2.7 \mu \mathrm{m}$ & 0.11 \\
12 & 63.7 & 100 & $2.7 \mu \mathrm{m}$ & 0.11 \\
13 & 119 & 50 & $2.7 \mu \mathrm{m}$ & 0.55 \\
14 & 119 & 50 & $2.7 \mu \mathrm{m}$ & 1.1 \\
15 & 119 & 50 & $10 \mathrm{~nm}$ & 0.11 \\
16 & 119 & 50 & $100 \mathrm{~nm}$ & 0.11 \\
17 & 119 & 600 & $0.2 \mathrm{~nm}$ & 0.11 \\
\hline
\end{tabular}




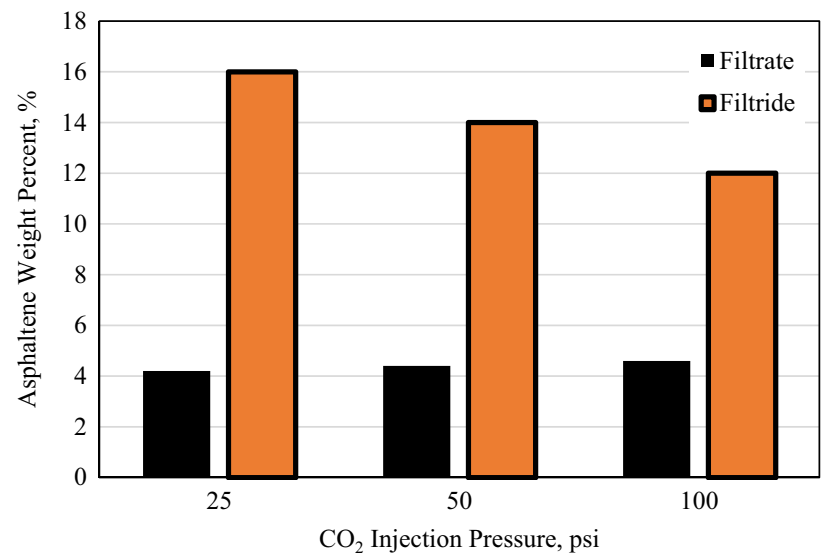

Fig. 10 Asphaltene weight percent at different $\mathrm{CO}_{2}$ injection pressures

\section{$\mathrm{CO}_{2}$ injection pressure effect}

The asphaltene weight percentage using different $\mathrm{CO}_{2}$ injection pressures for both the filtrate, which is the produced oil, and the filtride, which is the unproduced oil, is shown in Fig. 10. All experiments were conducted using the $469 \mathrm{cp}$ oil and the $2.7-\mu \mathrm{m}$ pore size filter membrane. As the $\mathrm{CO}_{2}$ injection pressure increased, the asphaltene weight percentage in the filtrate increased, and the asphaltene weight percentage in the filtride decreased. This is mainly due to the oil being forced through the filter membrane at the higher pressures. Since a higher percentage of the oil is mobilized through the membrane at the higher pressure, the asphaltene that manages to pass through the membrane becomes higher as well, which in turn results in a larger asphaltene weight percentage in the filtrate at higher pressures compared to the lower ones. Since the asphaltene weight percentage increased in the filtrate at higher pressures, it is expected that the asphaltene weight percent in the filtride will be less in the higher

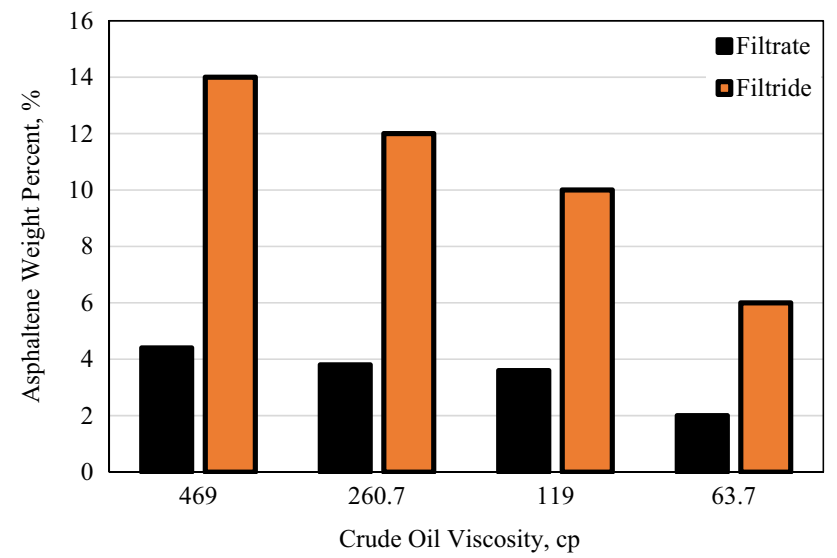

Fig. 11 Asphaltene weight percentage using different crude oil viscosity values pressures experiments than in the lower pressures, as can be observed in the results. The asphaltene weight percentage in the filtride represents the asphaltene that will remain in the reservoir pores, which will cause asphaltene problems in the reservoir, mainly asphaltene buildup and pore plugging.

\section{Oil viscosity effect}

The effect of changing oil viscosity on the asphaltene weight percentage in both the filtrate and the filtride is shown in Fig. 11. All experiments were conducted at $100 \mathrm{psi} \mathrm{CO}_{2}$ injection pressure using the $2.7-\mu \mathrm{m}$ pore size filter membrane. Decreasing the oil viscosity resulted in a decrease in the asphaltene weight percentage in both the filtrate and the filtride. This is mainly due to the decrease in the overall asphaltene weight percentage in the crude oil as the viscosity decreases, which was shown in the crude oil that was analyzed before running the filtration experiments in Fig. 9. The asphaltene concentration in the filtride was higher for all experiments than the asphaltene weight percentage in the filtrate. This is mainly due to the percentage of asphaltene that managed to be mobilized through the filter membrane. This is a strong indication that asphaltene instability may occur in many types of crude oils, regardless of the viscosity of the crude oil.

\section{Filter membrane pore size effect}

The effect of varying the asphaltene weight percent was investigated using 2700-, 100-, 10-, and 0.2-nm filter membrane pore sizes. The asphaltene weight percentage for the filtrate and the filtride for all the pore sizes is shown in Fig. 12. All the experiments were conducted using 100 psi $\mathrm{CO}_{2}$ injection pressure initially and $469 \mathrm{cp}$ crude oil. For the 100- and 10-nm filter membranes, the oil could not extrude through the filter membranes at that pressure, and thus, the

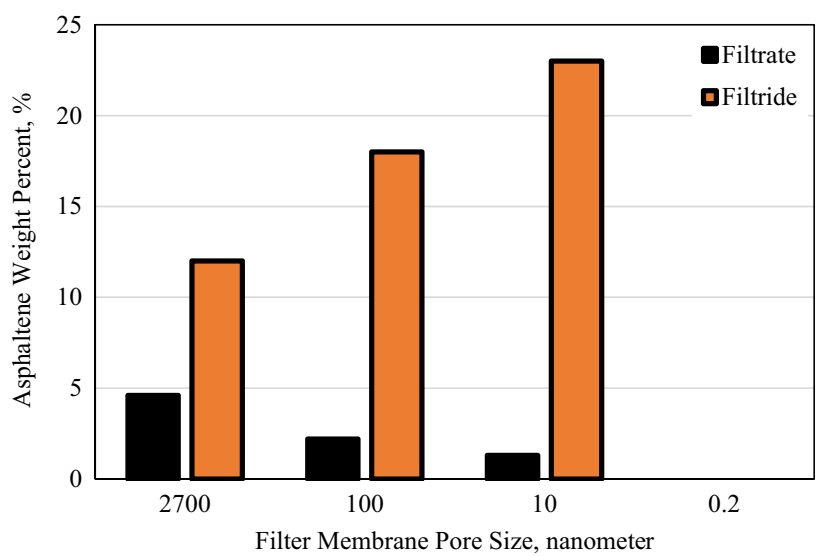

Fig. 12 Asphaltene weight percent using different filter membrane pore sizes 
pressure was increased in $50 \mathrm{psi}$ increments until it reached $300 \mathrm{psi}$ where the oil began to produce. The results for the 0.2-nm filter membrane will be explained later on. According to the Yen-Mullins asphaltene model, as the oil becomes heavier, the asphaltene in the oil becomes larger in diameter, reaching more than $5 \mathrm{~nm}$ in size per cluster. This will impact the ability of the asphaltene to extrude through the filter membrane. This can be observed clearly in the results obtained for the different pore sizes. As the filter membrane pore size decreased, the asphaltene weight percentage in the filtrate decreased as well, while the asphaltene weight percentage in the filtride increased. This is mainly due to the smaller pore sizes restricting the flow of the asphaltene due to the asphaltene diameter being very close to the pore size of the filter membrane, or perhaps even larger than it is. Some of the asphaltene particles that have not formed dense clusters tend to pass through the filter membranes, while the majority of the asphaltene concentration remains. Due to the increase in the asphaltene present in the filtride compared to the crude oil itself, the asphaltene concentration will become extremely high in the filtride, reaching values much higher than the original asphaltene concentration in the crude oil, which was $5.73 \%$ for $469 \mathrm{cp}$ oil. Based on the results, asphaltene instability will be much more severe in the smaller nanopores compared to the larger pores, which shows the severity of the damage that asphaltene may cause in the nanopores of the unconventional reservoirs.

When the pore size is too small, the oil will propagate through the pores at a lower rate and with more difficulty. This will result in asphaltene instability and will promote asphaltene precipitation and flocculation. The main factors impacting asphaltene instability in the smaller pores are the inability of the oil to propagate through the pores easily and the longer interaction of the $\mathrm{CO}_{2}$ with the crude oil when the pores are too small. As the asphaltene flocculates, it begins to form large clusters. When the clusters deposit, the size of the pores will influence the ability of the asphaltene to pass through it. If the pore size is too small, only a low percentage of asphaltene will be able to extrude through it, while the remaining percentage will begin to deposit in the pores and create asphaltene buildups. The larger the pore size, the lower the severity of asphaltene buildups due to the ability of the asphaltene cluster to pass through the larger pores.

When undergoing the experiment using the $0.2-\mathrm{nm}$ filter membrane shown in Fig. 12, 100 psi was used initially to displace the crude oil. No oil was produced from the membrane, however, due to the extremely small pore size. The pressure was maintained at $100 \mathrm{psi}$ for $2 \mathrm{~h}$ with no oil recovery. The pressure was then increased using $50 \mathrm{psi}$ increments up to $600 \mathrm{psi}$. For each pressure increment, the $\mathrm{CO}_{2}$ injection was undergone for $30 \mathrm{~min}$. The $600 \mathrm{psi}$ pressure was maintained for $4 \mathrm{~h}$; however, a pressure reduction was observed after $30 \mathrm{~min}$ of injection at $600 \mathrm{psi}$ until the pressure reached

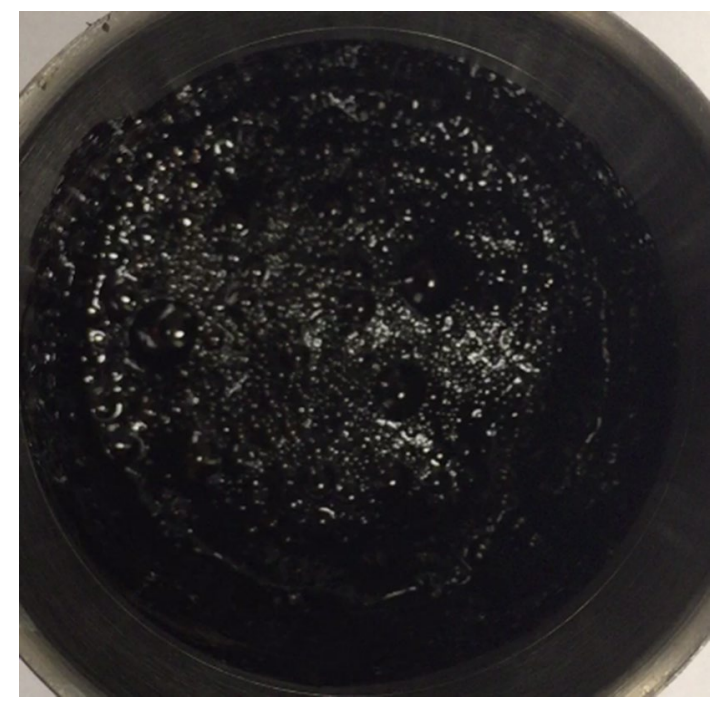

Fig. $13 \mathrm{CO}_{2}$ dissolved in the crude oil being liberated

$500 \mathrm{psi}$ after $4 \mathrm{~h}$. The filtration apparatus was tested for leakages using a high-accuracy pressure gauge, and no leakages were observed. The test was concluded after no oil production was obtained. When the filtration vessel was opened to obtain the crude oil, it was observed that the oil volume had increased significantly, and bubbles could be seen forming in the oil. Figure 13 shows the bubble formed in the oil when it was retrieved from the filtration vessel after concluding the test.

At the higher pressure, the oil swelled due to $\mathrm{CO}_{2}$ becoming soluble in the oil. This resulted in a decrease in the $\mathrm{CO}_{2}$ pressure applied. Once the pressure was relieved, the $\mathrm{CO}_{2}$ began liberating from the oil, and finally, the oil volume returned to its original amount. No oil was produced from the 0.2 -nm experiments, however, due to the extremely small pore sizes.

Based on the experiments conducted, the asphaltene could not propagate through the $0.2-\mathrm{nm}$ pore size. Also, a high percentage of asphaltene could not extrude through the 10 -nm pores. This indicates that the majority of asphaltene clusters ranged in size between $0.2 \mathrm{~nm}$ to greater than $10 \mathrm{~nm}$. When the asphaltene deposits on the filter membrane, it begins to build up, and thus, it increases in size. This is the main reason behind an increase in asphaltene concentration, even in the largest pore size.

\section{Asphaltene filter cake formation and thickness}

The filter cake is the part of the oil that will not pass through the filtration membrane and thus will not be produced; it partially represents the asphaltene, along with other high molecular weight components, that will not be mobilized by the $\mathrm{CO}_{2}$. As the filter cake begins to form, the flow rate will 
decrease until it reaches stabilization, where the filter cake has been created, and then either increases slightly or ceases to increase further. The time for the filter cake formation can be defined as the time starting from the initial decline in the flow rate after the first data point until the flow reached stabilization.

Measurement of the filter cake thickness was conducted using both a high-accuracy needle apparatus and a highaccuracy caliper. The filter cake was measured immediately after concluding the experiment to avoid movement of the asphaltene or contamination of the filter membrane due to exposure to the atmosphere. Measurements were recorded for different sections of the filter membrane, and the largest value recorded was taken as the filter cake thickness for each experiment. After the filter cake thickness was recorded, a high-resolution image of the filter membrane was taken for further analysis, and the filter membrane was vacuum-sealed for long-term storage.

Figure 14 shows the results for the filter cake thickness. The filter cake represents asphaltene buildup. This buildup is one of the major asphaltene problems in the field and can cause severe operational and production drawbacks during oil recovery. The highest thickness was obtained for the highest viscosity oil at the lowest $\mathrm{CO}_{2}$ injection pressure. The filter cake thickness decreased with the increase in $\mathrm{CO}_{2}$ injection pressure and with the decrease in oil viscosity. This is mainly due to the higher asphaltene concentration found in the highest viscosity oil, which resulted in a thicker filter cake formation on the filter membrane. When correlating the filter cake buildup to the asphaltene visualization experiments, it is clear that a common trend can be observed. This indicates that the asphaltene visualization experiments can be a strong tool to indicate asphaltene problems.

After conducting each experiment, high-resolution images of each of the filter membranes were taken and analyzed to calculate the area of the filter membrane that had no oil in it. The pictures were taken immediately after the experiment was done to avoid oil movement that would affect the integrity of the results. The area was calculated as both a value in $\mathrm{cm}^{2}$ and also as a percentage of the overall area of the filter membranes. Figure 15 shows the images for all the filter membranes, and the breakthrough areas outlined in red. As the oil viscosity decreased, the breakthrough area increased, and also as the $\mathrm{CO}_{2}$ injection pressure increased, the area increased. These results can also be compared to the filter cake thickness, which was discussed earlier.

\section{Conclusions}

This research undergoes two sets of experiments, including asphaltene visualization and asphaltene filtration experiments, to investigate asphaltene stability in crude oil under different conditions. The main conclusions obtained from this research are as follows:

- Asphaltene plugging in nanopores was found to be extremely severe, which was evident from the asphaltene concentration in the filtride. This is mainly due to the size of the pores becoming closer to the size of asphaltene clusters, which made it difficult for the asphaltene to extrude through the pores.
Fig. 14 Filter cake thickness for different oil viscosities at different $\mathrm{CO}_{2}$ injection pressures

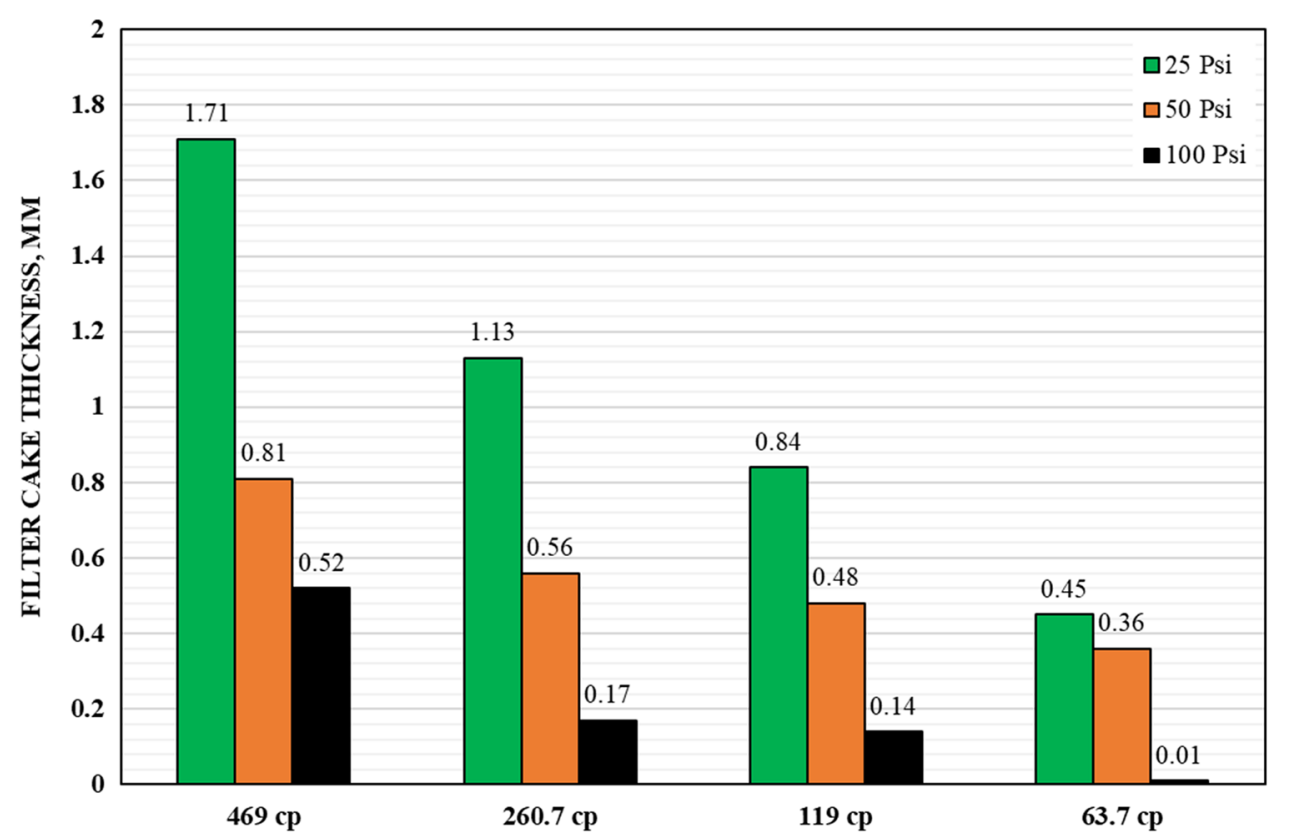


Fig. 15 Filtrate breakthrough areas and overall breakthrough percentages

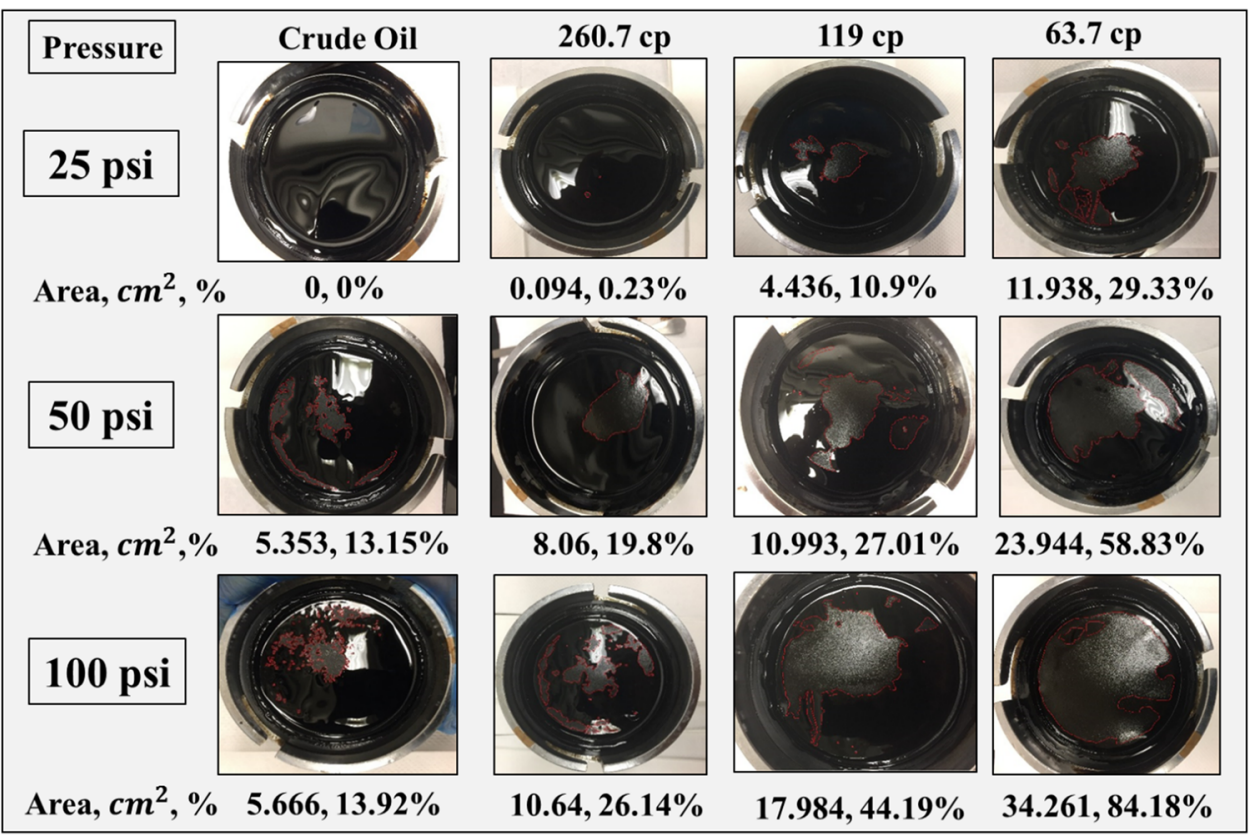

- Asphaltene deposition was found to be a stage-wise process, which begins with asphaltene precipitation then flocculation and finally ends with deposition. Different conditions will impact the severity and rate of these three stages.

- Asphaltene buildup was observed in all experiments, even the experiments using the 2.7-micron filter membrane. This shows that asphaltene buildup and pore plugging can be a severe problem in both conventional reservoirs with large pores and unconventional reservoirs with nanopores.

- Asphaltene buildup was observed even for the lightest crude oil, $63.7 \mathrm{cp}$. This shows that asphaltene problems can arise even in light crude oils and will not be limited only to heavy oils. As the oil viscosity increased, the asphaltene concentration also increased. This impacted the rate of asphaltene precipitation, flocculation, and deposition. This also had a strong impact on asphaltene buildup.

Acknowledgements The author wishes to thank Missouri University of Science and Technology for its support through the Chancellors Distinguished Fellowship.

Open Access This article is distributed under the terms of the Creative Commons Attribution 4.0 International License (http://creativeco mmons.org/licenses/by/4.0/), which permits unrestricted use, distribution, and reproduction in any medium, provided you give appropriate credit to the original author(s) and the source, provide a link to the Creative Commons license, and indicate if changes were made.

\section{References}

Akbarzadeh $\mathrm{K}$ et al (2007) Asphaltenes_-problematic but rich in potential. Oilfield Rev 19(2):22-43

Al-Ghazi S, Lawson J (2007) Asphaltene cleanout using vibrablaster tool. Soc Pet Eng. https://doi.org/10.2118/110972-MS

D-4124-97 (2019) ASTM. Standard test methods for separation of asphalt into four fractions

De Boer RB et al (1995) Screening of crude oils for asphalt precipitation: theory, practice, and the selection of inhibitors. SPE Prod Facil 10(1):55-61

Escobedo J, Mansoori GA (1997) Viscometric principles of onsets of colloidal asphaltene flocculation in paraffinic oils and asphaltene micellization in aromatics. SPE Prod Facil 12(2):116-122

Fakher SM (2019) Asphaltene stability in crude oil during carbon dioxide injection and its impact on oil recovery: a review, data analysis, and experimental study, Masters theses 7881

Fakher S, Imqam A (2018) Investigating and mitigating asphaltene precipitation and deposition in low permeability oil reservoirs during carbon dioxide flooding to increase oil recovery. Soc Pet Eng. https://doi.org/10.2118/192558-MS

Fakher S, Imqam A (2019) Asphaltene precipitation and deposition during $\mathrm{CO}_{2}$ injection in nano shale pore structure and its impact on oil recovery. Fuel J 273:1029-1039. https://doi.org/10.1016/j. fuel.2018.10.039

Fakher S et al (2017) Novel mathematical models to predict preformed particle gel placement and propagation through fractures. Soc Pet Eng. https://doi.org/10.2118/187152-MS

Fakher $\mathrm{S}$ et al (2018a) Investigating the viscosity reduction of ultraheavy crude oil using hydrocarbon soluble low molecular weight compounds to improve oil production and transportation. Soc Pet Eng. https://doi.org/10.2118/193677-MS

Fakher $S$ et al (2018b) Increasing production flow rate and overall recovery from gas hydrate reservoirs using a combined steam flooding-thermodynamic inhibitor technique. Soc Pet Eng. https ://doi.org/10.2118/191179-MS

Fakher S et al (2019) A comprehensive review on gas hydrate reservoirs: formation and dissociation thermodynamics and rock and

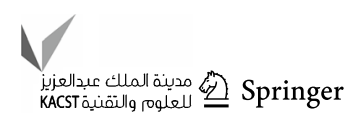


fluid properties. In: International petroleum technology conference. https://doi.org/10.2523/19373-ms

Fan T et al (2002) Evaluating crude oils by SARA analysis. In: Presented at the SPE/DOE improved oil recovery symposium, Tulsa, Oklahoma, 13-17 April. SPE-75228-MS

Forte E, Taylor SE (2014) Thermodynamic modelling of asphaltene precipitation and related phenomena. Adv Colloid Interface Sci 217:1-12

Goel P et al (2017) Prediction of API values of crude oils by use of saturates/aromatics/resins/asphaltenes analysis: computational-intelligence-based models. Soc Pet Eng J. https://doi. org/10.2118/184391-PA

Goual L (2012) Petroleum asphaltenes, crude oil emulsions-composition stability and characterization. ISBN: 978-953-51-0220-5

Goual L, Abudu A (2009) Predicting the adsorption of asphaltenes from their electrical conductivity. Energy Fuel 24:469-474

Groenzin H, Mullins OC (2000) Molecular size and structure of asphaltenes from various sources. Energy Fuels 14(3):677-684

Hannisdal A, Ese MH, Hemmingsen PV, Sjoblom J (2006) Particlestabilizedemulsions: effect of heavy crude oil components preadsorbed onto stabilizing solids. Colloids Surf A Physicochem Eng Asp 276:45-58

Hernandez ME, Vives MT, Pasquali J (1983) Relationships among viscosity, composition, and temperature for two groups of heavy crudes from the eastern Venezuelan basin. Org Geochem 4:173-178

Islas-Flores CA, Buenrostro-Gonzalez E et al (2005) Comparisons between open column chromatography and HPLC SARA fractionations in petroleum. Energy Fuels 19(5):2080-2088

Jamaluddin AKM et al (2000) Experimental and theoretical assessment of the asphaltene precipitation characteristics of the Sahil field under a proposed gas injection scheme. In: Paper SPE \# 87292 presented at the SPE Conference and Exhibit, 15-18 October 2000, Abu Dhabi, UAE

Jewell D et al (1972) Ion-exchange, coordination, and adsorption chromatographic separation of heavy-end petroleum distillates. Anal Chem 44(8):1391-1395

Jha NK et al (2014) Characterization of crude oil of upper Assam field for flow assurance. In: Presented at the SPE Saudi Arabia section annual technical symposium and exhibition, Al-Khobar, Saudi Arabia, 21-24 April. SPE-172226-MS

Kalantari-Dahagi A et al (2006) Formation damage due to asphaltene precipitation resulting from $\mathrm{CO}_{2}$ gas injection in Iranian carbonate reservoirs. Soc Pet Eng. https://doi.org/10.2118/99631-MS

Kariznovi M, Nourozieh H, Abedi J, Jamialahmadi M, Shahrabadi A (2012) Experimental, modeling, and optimization of asphaltene deposition and adsorption in porous media. Can J Chem Eng 90:1356

Keshmirizadeh E, Shobeirian S, Memariani M (2013) Determination of saturates, aromatics, resins and asphaltenes (SARA) fractions in Iran crude oil sample with chromatography methods: study of the geochemical parameters. J Appl Chem Res 7(4):15-24

Kharrat A et al (2013) Asphaltene content measurement using an optical spectroscopy technique. Energy Fuels 27(5):2452-2457. https ://doi.org/10.1021/ef400050y

Kim ST et al (1990) The role of asphaltene in wettability reversal. In: SPE paper presented at the SPE Annual Technical Conference and Exhibition, 1990, New Orleans, Louisiana

Kord S, Miri R, Ayatollahi S, Escrochi M (2012) Asphaltene deposition in carbonate rocks: experimental investigation and numerical simulation. Energy Fuels 26(10):6186-6199. https://doi.org/10.1021/ ef300692e

Kordestany A, Hassanzadeh H, Abedi J (2019) An experimental approach to investigating permeability reduction caused by solvent-induced asphaltene deposition in porous media. Can J Chem Eng 97(1):361-371
Leontaritis K, Mansoori GA (1987) Asphaltene flocculation during oil production and processing: A thermodynamic colloidal model. In: SPE international symposium on oilfield chemistry. Society of Petroleum Engineers

Lichaa PM, Herrera L (1975) Electrical and other effects related to the formation and prevention of asphaltene deposition problem in Venezuelan crudes. In: SPE oilfield chemistry symposium. Society of Petroleum Engineers

Mannistu KD, Yarranton HW, Masliyah JH (1997) Solubility modeling of asphaltenes in organic solvents. Energy Fuels 11(3):615-622

Mansoori GA (1996) Asphaltene, resin, and wax deposition from petroleum fluids: mechanisms and modeling. Arab J Sci Eng 21(4B):707-723

Mendoza De La Cruz JL, Argüelles-Vivas FJ, Matías-Pérez V, DuránValencia CD, López-Ramírez S (2009) Asphaltene-induced precipitation and deposition during pressure depletion on a porous medium: an experimental investigation and modeling approach. Energy Fuels 23(11):5611-5625. https://doi.org/10.1021/ef900 6142

Miadonye A, Evans L (2010) The solubility of asphaltenes in different hydrocarbon liquids. Pet Sci Technol J. https://doi. org/10.1080/10916460902936960

Mishra VK et al (2012) Downhole fluid analysis and asphaltene nanoscience coupled with VIT for risk reduction in black oil production. In: Presented at the SPE annual technical conference and exhibition, San Antonio, USA, 8-10

Mohammed R et al (2017) Simulation study of asphaltene deposition and solubility of $\mathrm{CO}_{2}$ in the brine during cyclic $\mathrm{CO}_{2}$ injection process in unconventional tight reservoirs. Int $\mathrm{J}$ Geol Environ Eng 11(6):485-500

Monger TG, Fu JC (1987) The nature of $\mathrm{CO}_{2}$-induced organic deposition. In: SPE paper \# 16713 presented at the SPE annual technical conference and exhibition, Houston, TX

Moradi S et al (2012) Investigation of asphaltene precipitation in miscible gas injection processes: experimental study and modeling. Braz J Chem Eng 29(3):665-676

Mullins OC (2011) The modified yen model. Energy Fuels 24(4):2179-2207

Punase A et al (2016) The polarity of crude oil fractions affects the asphaltenes stability. Soc Pet Eng. https://doi.org/10.2118/18042 3-MS

Rassamdana HB et al (1996) Asphaltene flocculation and deposition: I. The onset of precipitation. AIChE J 42(1):10-22

Rogel E et al (1999) Asphaltene stability in crude oils. Soc Pet Eng. https://doi.org/10.2118/53998-MS

Shedid and Zekri (2006) Formation damage caused by simultaneous sulfur and asphaltene deposition. Soc Pet Eng. https://doi. org/10.2118/86553-PA

Shen and Sheng (2018) Experimental and numerical study of permeability reduction caused by asphaltene precipitation and deposition during $\mathrm{CO}_{2}$ huff and puff injection in Eagle Ford shale. Fuel 211:432-445. https://doi.org/10.1016/j.fuel.2017.09.047

Soroush S et al (2014) A comparison of asphaltene deposition in miscible and immiscible carbon dioxide flooding in porous media. Soc Pet Eng. https://doi.org/10.2118/169657-MS

Speight JG (1999) The chemical and physical structure of petroleum: effect on recovery operations. J Pet Sci Eng 22:3-15

Speight JG et al (1985) Molecular weight and association of asphaltenes: a critical review. Revue De L'Institut FrancaisDu Petrole 40(1):51-61

Sun $\mathrm{H}$ et al (2019) Competitive adsorption of $\mathrm{CO}_{2}$ over $\mathrm{N}_{2}$ in asphaltene slit nanopores studied by molecular simulation. Energy Fuels J. https://doi.org/10.1021/acs.energyfuels.7b02656

Thomas D et al (1995) Controlling asphaltene deposition in oil wells. Soc Pet Eng. https://doi.org/10.2118/25483-PA 
Uetani T (2014) Wettability alteration by asphaltene deposition: a field example. Soc Pet Eng. https://doi.org/10.2118/171788-ms

Wang $\mathrm{S}$ et al (2016) Characterization of produced and residual oils in the $\mathrm{CO}_{2}$ flooding process. Energy Fuels 30(1):54-62. https://doi. org/10.1021/acs.energyfuels.5b01828

Yen A et al (2001) Evaluating asphaltene inhibitors: laboratory tests and field studies. In: Paper SPE-65376-MS presented at the SPE international symposium on oilfield chemistry, Houston, TX
Zendehboudi S et al (2014) Asphaltene precipitation and deposition in oil reservoirs - technical aspects, experimental and hybrid neural network predictive tools. Chem Eng Res Des 92(5):857-875

Publisher's Note Springer Nature remains neutral with regard to jurisdictional claims in published maps and institutional affiliations. 